had the typical facial appearance with a small upturned nose, long philtrum, a rather large mouth with a thin upper lip, low set ears, and epicanthic folds. Mother had smoked between 20 and 40 cigarettes a day during pregnancy but gave no definite history of taking alcohol. When I discussed this with her she said, with conviction that she did not like alcohol and she stuck to soft drinks. She added, 'but it's the child's father who drinks, in fact the only time he visited the child he was drunk'. She said it was a family joke that they thought that the child's red nose was due to her father being an alcoholic.

Perhaps if we also looked into the alcoholic intake of the sperm we might have better understanding of the syndrome. I understand from my senior house officer that Carthage recognised that it was a bad thing to take wine on the nuptial night. ${ }^{2}$

EILEEN E HILL East Birmingham Hospital, Birmingham B9 5ST

Professor Smithells and Dr Smith comment:

Dr Hill is not the first to report the features of fetal alcohol syndrome in the offspring of a mother who denies taking alcohol. Hanson, Streissguth, and $\mathrm{Smith}^{3}$ identified 11 newborns who were 'abnormal with features of FAS'. Little or no alcohol had been consumed by two of the mothers in the month before pregnancy and by four during the first five months of pregnancy. It is therefore at least possible that there are phenocopies of fetal alcohol syndrome not associated with alcohol. Hence our caution in subscribing to the notion of a specific syndrome.

Histories of alcohol intake are notoriously inaccurate if routine questions are used ${ }^{4}$ and we must all judge the reliability of any information given to us by parents. Even after fairly intensive questioning, about half the mothers of thalidomide damaged children denied having taken the drug, although the analogy with alcohol is not particularly close.

The role of the drunken father is even more difficult to study. In Carthage and in Greece the wedding reception was indeed 'dry', 5 and the lameness of the god Vulcan was attributed to his having been sired by Jupiter when in a drunken stupor. ${ }^{6}$ The old testament was content to advise against alcohol during pregnancy (Judges 13:7). We have no great difficulty envisaging an inebriated sperm weaving its way up to the fallopian tube and, with one last supreme lurch, penetrating a chaste and unsuspecting egg. We have more difficulty believing that the dose of ethanol thereby delivered could have a profound influence on fetal growth for nine months and on embryological events still weeks away.

But we are men, and Dr Hill is not!

\footnotetext{
References

' Smithells RW, Smith IJ. Alcohol and the fetus. Arch Dis Child 1984;59:1113-4.

2 Jones KL, Smith DW. Recognition of the fetal alcohol syndrome in early infancy. Lancet 1973;ii:999-1001.

${ }^{3}$ Hanson JW, Streissguth AP, Smith DW. Effects of moderate
}

alcohol consumption during pregnancy on fetal growth and morphogenesis. J Pediatr 1978;92:457-60.

${ }^{4}$ Barrison IG, Viola L, Murray-Lyon IM. Do housemen take an adequate drinking history. Br Med $J$ 1980;ii:1040.

${ }^{5}$ Haggard HW, Jellinek EM. Alcohol explored. Doubleday Doran, New York. 1942.

${ }^{6}$ Rasmussen BB, Christensen N. Alkohol og fosterskader. Ugeskrift for Laeger (Copenhagen). 1978;140:282-4.

\section{High and conventional ventilation rates in the newborn}

Sir,

Dr Field and colleagues' interesting study ${ }^{1}$ on the effect of mechanical ventilation at rates of less than 50 and of $100 /$ minute on oxygenation and spontaneous respiration prompts three questions.

(1) What flow rates were used during the studies and were they altered in the transition from slower to more rapid rates in order to maintain the other ventilator settings constant?

(2) How can the authors exclude the possibility that the changes in oxygenation seen during transition from slow to fast rates were not a reflection of changes in mean airway pressure? For instance if flow was increased at fast rates, a consequent increase in mean airway pressure could account for all or part of the increased oxygenation documented in six infants.

(3) How many instances have the authors documented of the pattern of reflex expiratory effort against ventilator inflation which they cited ${ }^{2}$ and can they confirm that such babies develop pneumothoraces?

\section{W TaRnow-Mordi and A Wilkinson John Radcliffe Hospital, Oxford $O X 3$ 9DG}

\section{Dr Field and Professor Milner comment:}

We thank Drs Tarnow-Mordi and Wilkinson for their comments and, in answer to the points they have raised, we are able to add the following information;

(1) Ventilator flow rates were adjusted at the start of each study to compensate for the loss of bias flow through the pneumotachograph, and then remained constant for the duration of the investigation. They were approximately 6 litres/minute.

(2) We have looked formally at the effect of fast ventilator rates on mean airway pressure and found that the Draeger Babylog ventilator produces no significant variation in mean airways pressure when used over the range of ventilator rates employed in this study. ${ }^{3}$ We confirmed this finding in the babies reported in this study.

Some workers feel that the use of fast ventilator rates leads to an inadvertent positive end expiratory pressure within the lungs which affects gaseous exchange. Evidence in support of this phenomenon has been provided mainly by in vitro ${ }^{4}$ or animal studies. ${ }^{5}$ All our infants were in the acute phase of idiopathic respiratory distress syndrome and 
therefore any such effect should, for the most part, have been minimised since in this situation compliance is low and the time constant of the respiratory system short.

(3) We have carried out a systematic assessment of the effects of both respiratory rate and inspiratory to expiratory ratio on the pattern of interaction between spontaneous and mechanical ventilation. Both of these parameters can be used to manipulate the infant's pattern of interaction in the vast majority of cases. We did not find the pattern of active expiration against the ventilator inevitably produced a pneumothorax.

\section{References}

1 Field D, Milner AD, Hopkin IE. High and conventional rates of positive pressure ventilation. Arch Dis Child 1984;59:1151-4.

2 Greenough A, Morley CJ, Wood S, Davis JA. Pancuronium prevents pneumothoraces in ventilated premature infants who actively expire against positive pressure ventilation. Lancet $1984 ; \mathbf{i}: 1-3$.

${ }^{3}$ Ficld $\mathrm{D}$, et al. Calculation of mean airway pressure during neonatal intermittent positive pressure ventilation and high frequency positive pressure ventilation. Pediatric Pulmonology 1985 ; in press.

${ }^{4}$ Simbruner G, Gregory GR. Performances of neonatal ventilators: the effects of the changes in resistance and compliance. Crit Care Med 1981;9:509-13.

5 Cartwright DW, Willis MM, Gregory GA. Functional residual capacity and lung mechanics at different levels of mechanical ventilation. Crit Care Med 1984;12:422-7.

\section{Neonatal auditory brainstem response cannot reliably diagnose brainstem death}

Sir,

Dear and Godfrey ${ }^{1}$ are quite correct 'to sound a note of caution regarding the interpretation of the auditory brainstem response' (or brainstem auditory evoked potential) in relation to diagnosis of brainstem death. Neurophysiological investigations are a measure of function of the nervous system and their dynamic aspects must be appreciated. Loss of later brainstem auditory evoked potential components after a cerebral insult need not necessarily imply structural damage to the whole brainstem and may occasionally be reversible. ${ }^{2} 3$ Similarly an isoelectric electroencephalogram soon after a period of, for example, cerebral ischaemia, may only imply temporary 'paralysis' and complete recovery of cortical function can occur. The brainstem auditory invoked potential, as with other neurophysiological tets, is a useful clinical sign especially in comatose patients. As with any one clinical sign, it should be considered in the context of the history and other clinical signs.

Serial electroencephalograms after a cerebral insult have proved invaluable in assessing the degree and reversibility of damage to the cerebral cortex. In these circumstances the brainstem auditory evoked potential findings combined with the electroencephalogram provide information about cortical and brainstem function unobtainable by clinical tests alone. It would be a pity if a valuable clinical sign such as the auditory evoked potential were considered in isolation and if the mistake of expecting the loss of these components alone to diagnose brainstem death ${ }^{3}$ were continued. In our experience serial brainstem auditory evoked potentials together with other neurophysiological investigations do offer reliable prognostic information even in the neonatal period.

\section{References}

1 Dear PRF, Godfrey DJ. Neonatal auditory brainstem response cannot reliably diagnose brainstem death. Arch Dis Child 1985:60:17-9.

2 Boyd SG, Harden A, Pampiglione G. Serial BAEP and EEG studies in acute encephalopathies of childhood. EEG Clin Neurophysiol 1984;58:16P.

${ }^{3}$ Taylor M, Houston BD, Lowry NJ. Recovery of auditory brain-stem responses after a severe hypoxic ischemic insult. $N$ Engl J Med 1983;309:1169-70.

S G Boyd AND A Harden Hospital for Sick Children, Great Ormond Street, London WCIN $3 \mathrm{JH}$

\section{Continuous measurement of subarachnoid pressure in the severely asphyxiated newborn}

Sirs,

The study by Levene and Evans ${ }^{1}$ contains some interesting observations. The underlying supposition is that there is benefit in reducing intracranial pressure (in a way that improves cerebral perfusion pressure) after birth asphyxia. Although this is a plausible notion, I know of no human experimental evidence to support it adequately. I acknowledge that there would be considerable difficulty in obtaining such evidence, which would require a study incorporating more badly asphyxiated babies than most of us will see in a lifetime, but it is surely premature to regard as unethical withholding the treatment which they 'tentatively recommend'. They might argue that mannitol should only be given if intracranial pressure monitoring is performed, and that a procedure as invasive as placing a subdural catheter could not be justified if the information provided was ignored; but in that case how do we proceed? I would be interested to know what experimental approaches to this important issue they think might reasonably be conducted.

P R F DEAR St James's University Hospital, Leeds LS9 $7 T F$

Drs Levene and Evans comment:

We thank Dr Dear for his interest in our paper. Our approach to the problem of postasphyxial cerebral oedema has been to ask three questions:

(1) Does raised intracranial pressure occur after birth asphyxia? 